\title{
Poder estatal y dominación de género: sus representaciones en La linterna roja (China, 1991) de Zhang Yimou
}

\section{Battagliese, Rodolfo}

Resumen: El film puede interpretarse como una representación estética de los minuciosos mecanismos del ejercicio del poder que tienen por finalidad y tal como lo plantea Michel Foucault en los distintos tramos de su obra, disciplinar y normalizar a aquellos que pretenden cuestionarlo. Foucault lo planteó refiriéndose a las formas modernas del ejército, la escuela, las prisiones, hospitales, que podemos extender a las relaciones de género, temática de la que no se ocupó el autor.

\section{En la Linterna roja, las}

representaciones fílmicas del autoritarismo no sólo están asociadas a la vida cotidiana de mujeres subordinadas a la ley del varón, tanto en el plano social como cultural, sino que pueden interpretarse, como la construcción de un tipo de poder disciplinador que atraviesa los distintos regímenes políticos de la historia de China del siglo XX. Filmada poco tiempo después de la represión en la plaza de Tiananmen, las potentes imágenes sobre el poder y el patriarcado representan las normas morales tradicionales del Confucionismo y resignifican por extensión, a las de la China comunista.

Palabras clave: Poder - autoritarismo - patriarcado - Confucionismo - China comunista.

$\left({ }^{*}\right)$ Profesor de Historia egresado de la Facultad de Filosofía y Letras (UBA). Docente e Investigador de la UBA, se especializa en el estudio de las representaciones del mundo del trabajo en el cine europeo.

Introducción

\section{Cuadernos del Centro de Estudios de Diseño y Comunicación Nº 68}

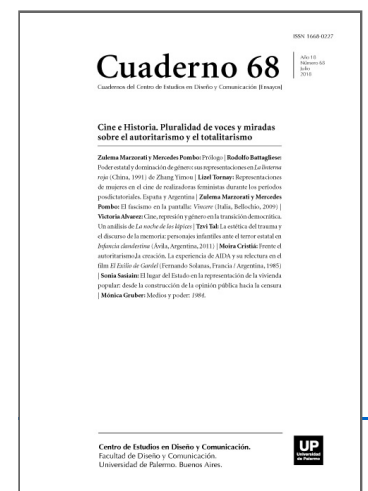

ISSN: 1668-0227

Cine e Historia.

Pluralidad de voces y

miradas sobre el

autoritarismo y el

totalitarismo

Año XVIII, Julio 2018, Buenos Aires, Argentina | 148 páginas

descargar PDF ver índice de la publicación

Ver todos los libros de la publicación

compartir en Facebook

Esta obra está bajo una Licencia Creative

Commons Atribución-NoComercial-

Compartirlgual 4.0 Internacional 
"Siempre he pensado que ruedo mis películas para mis compatriotasporque mis sentimientos y mi idea de la vida nacen aquíy me parece que sólo aquí pueden tener su resonancia completa"Zhang Yimou (Alcaine y MeiHsing, 1998, p. 146)

Zhang Yimou nació en 1950 en China, y formó parte de la denominada "Quinta Generación” de directores formados en la Escuela de Cine de Pekín, fundada en 1956 y cuya punta de lanza encabezaría Cheng Kaige, junto a otros destacados cineastas como Hu Mei y Wu Ziniu. Marcados por el trauma de la Revolución Cultural1 , vieron en el cine una herramienta intelectual con la que expresar sus críticas hacia el régimen comunista. Fue una reacción, además, contra el cine propagandístico del Partido, creando a su vez, una voz propia, temática y estética, que miraba críticamente no sólo al poder, sino también a la estructura cultural de China. Para ello eligieron, entre otras estrategias, problemáticas relacionadas con el pasado pre comunista, que además les sirvieran como una forma de eludir la censura impuesta por el Régimen.

Zhang Yimou creció en una familia vigilada por el régimen maoísta, por haber apoyado a los nacionalistas que perdieron la guerra a finales de los cuarenta, convirtiéndolo en un blanco seguro de la acción de la censura que encontraba poco digeribles sus películas. No era para menos. Su primera participación en cine fue como director de fotografía de Tierra Amarilla (1984) de Chen Kaige, considerada como la primera película que hizo de la crítica al poder político comunista su principal bandera y que caracterizó a los cineastas de la Quinta Generación.

Es el más representativo de los directores chinos. Entre sus filmes más importantes se destacan: Sorgo rojo (1988), Ju Du (1989), Vivir (1994), la Joya de Shangai (1995), Ni uno menos (1999), Héroe (2002), La casa de las dagas voladoras (2004) La maldición de la flor dorada (2006), Una mujer, una pistola y una tienda de fideos chinos (2009), Las 13 flores de Nanking (2011) y Coming Home (2015). Además codirigió la ceremonia de apertura de los Juegos Olímpicos de Beijing 2008.

La linterna roja2, cierra una trilogía conformada por Sorgo Rojo y Ju Du/Semilla de Crisantemo, películas que tienen como temática principal el de seguir los pasos de mujeres enfrentadas a la sociedad tradicional China.

El film que analizaremos puede leerse como una representación estética de los minuciosos mecanismos del ejercicio del poder (poco tiempo después de la represión en la plaza de Tiananmen3 ), tal como lo plantea Michel Foucault $(1989,2002)$ en los distintos tramos de su obra, para disciplinar y normalizar a todos aquellos que pretenden cuestionarlo. Foucault lo planteó refiriéndose a las formas modernas del ejército, la escuela, las prisiones, hospitales y que podemos extender a las relaciones de género, temática de la que no se ocupó el autor.

El texto fílmico describe la sumisión cultural y social de la mujer china, consecuencia de la mentalidad feudal que imperó en ese país hasta no hace mucho y sitúa la acción a comienzos de la década del 20 del siglo pasado, durante la época que enfrenta a los "Señores de la guerra4".

El eje del relato gira alrededor de la historia de Songlian, una joven estudiante universitaria de 19 años que, a la muerte de su padre, decide a su pesar, convertirse en la concubina legal de un rico maestro que ya posee esposa y otras dos concubinas. Forzadas a competir entre ellas, las tres concubinas tratan continuamente de ganarse la atención y el afecto del Señor, quien se muestra poco en el film y desaparece de la pantalla en los 
momentos más densos del relato, pero que está siempre omnipresente, porque más que una persona, constituye la representación del poder y la ley.

El Sanheyuan (residencia típica de las clases altas formada por viviendas independientes) es el ambiente elegido por el director para representar ese poder asfixiante, claustrofóbico y en apariencia, protector.

En la película de Zhang Yimou las representaciones fílmicas del autoritarismo no sólo están asociadas a la vida cotidiana de mujeres subordinadas al poder del varón, tanto en el plano social como cultural, sino que pueden interpretarse, como la construcción de un tipo de poder, decíamos, disciplinador que atraviesa los distintos regímenes políticos de la historia de China del siglo XX. Las potentes imágenes sobre el poder y el patriarcado representan las normas morales tradicionales del Confucionismo y resignifican por extensión, a las de la China comunista.

Relaciones de poder y poder de género

Una joven llega a una casa imponente, a una especie de fortaleza descripta anteriormente. La joven fue comprada para ser la cuarta esposa del amo del castillo y debió abandonar la universidad. Al morir su padre, la madrastra le dijo que ya no podía mantenerla. Le ofreció una disyuntiva: ser la esposa única de un pobre o ser una esposa más (en realidad una concubina) de un rico. Eligió lo segundo. El Señor Chen ni siquiera la eligió. Su hombre de confianza se la compró a la madrastra. Al ingresar a la casa del amo, las esposas-concubinas lo primero que pierden es su nombre propio. Desde el momento en que entran se las reconoce por el número de llegada a la mansión: primera concubina, segunda, tercera, y así sucesivamente. La universitaria es la cuarta. Cuando haya más, seguirá la secuencia numé- rica. He aquí la primera pérdida de poder: estas mujeres son despojadas de su identidad. La casa del Señor Chen se desarrolla dentro de las estrictas reglas familiares y las tradiciones que todos deben seguir, tanto las sirvientas como las concubinas. En este microcosmos, el Señor no es sólo la ley, sino también el centro de todos los valores. Todo gira en torno a él. Cada concubina tiene sus propias dependencias edilicias. Un especie de casita dentro de la casa grande. Departamentos internos independientes compartiendo un patio común y sin cocina. Una especie de panóptico. Además, cada una tiene su propia sirvienta, independientemente de las sirvientas generales de la mansión. Las construcciones arquitectónicas forman parte de los dispositivos de poder y dan cuenta de ellos. Cuando Songlian, la cuarta concubina llega a la residencia es despreciada por una muchacha del servicio, Yan'er. El motivo es que esa joven es abusada por el señor (a quien no le alcanza con las esposas-concubinas, también somete sexualmente a algunas servidoras). La pequeña sirvienta, en su ingenuidad, había fantaseado que el señor se acostaba con ella porque la quería, y que ella accedería a ser concubina, pensaba que sería la cuarta, que ocuparía el lugar que ahora ocupa la ex-universitaria.

Las rivalidades que el amo siembra entre ellas no son aleatorias. Están al servicio del juego del poder. Las peleas divisorias internas amplían al poder hegemónico. La muchacha resentida es elegida como servidora personal de la flamante cuarta concubina.

La primera concubina tiene aproximadamente la misma edad que el amo, es decir, es vieja. Nunca más el esposo se acostará en su cama. No obstante, la "primera señora" comparte cada día la mesa familiar y circula libremente por la casa. Incluso, en ausencia del amo puede tomar alguna decisión, aunque únicamente en 
situaciones límites. De todos modos, es seguida de cerca (como todas) por el hombre de confianza del señor. La primera concubina tiene un hijo del amo, cuya edad es similar a la de la concubina más joven.

La segunda concubina es de edad madura. No es mayor como la primera ni joven como las dos últimas. Pero es vigorosa y astuta. Compite con las jóvenes. Ha tenido la desdicha de darle descendencia femenina al señor. Esto la descoloca respecto del poder. Sin embargo, trata de salvar la deficiencia siendo muy sumisa con el hombre y dando arteras estocadas que suelen descolocar a las mujeres que aún están en carrera.

La tercera concubina era la más apetecible hasta que llegó la ex-universitaria. Es joven, linda, alegre y canta como los ruiseñores. Había sido cantante lírica. Además, le dio al señor un hijo varón. Su orgullo era extremo, nunca pensó que el amo traería otra mujer y, cuando eso ocurre, estalla en celos e histeria. Justamente eso es lo que el poder necesita para reafirmarse: competencia entre las subordinadas. Mientras compitan y confabulen entre ellas, no lo harán contra él.

El título original de la película es Linternas rojas. Nosotros diríamos "faroles rojos", puesto que ese es el nombre que le damos a las típicas lámparas chinas. Las que le dan nombre al film son de aproximadamente un metro de diámetro por ochenta centímetros de alto. Se cuelgan de un trípode de la altura de un hombre. Cada atardecer, a una hora prefijada suena un gong. Entonces, cada concubina debe salir a la puerta de su casa interior acompañada por su sirvienta. Todas aguardan en actitud sumisa rodeando un patio central (centro del panóptico) donde se instala el hombre de confianza del señor portando un trípode en la mano izquierda y una lámpara roja en la derecha. La concubina jubilada también debe asistir a la ceremonia. Tiene que renovar y exponer, cada día, la humillación de no ser elegida. El portador de la lámpara se acerca a la casa de la mujer que el señor eligió para esa noche y coloca el trípode delante de su puerta. Cuelga el farol encendido para goce de la privilegiada de turno y escarnio de las demás. La sirvientita de la elegida, por más que odie a su señora, goza de la elección como si fuera propia, mira con altivez a las demás sirvientas. La concubina seleccionada arroja una mirada altanera a las demás concubinas, desde su precaria superioridad.

Durante las siguientes veinticuatro horas gozará de ciertos beneficios otorgados por un poder limitado y transitorio, pero poder al fin. Ella decidirá qué se comerá en la casa durante su efímero reinado. Es el momento de ajustar cuentas y hacerle comer a las otras todo aquello que detestan. Los sirvientes obedecerán sus órdenes y esa noche, por supuesto, recibirá la visita del señor. Ser elegida significa acercarse a las densidades del ejercicio del poder. La relación sexual es lo de menos. El director de la película deja bien en claro que ahí lo importante es el dominio sobre las demás, tener que satisfacer el deseo del hombre es algo secundario. El deseo de ella no cuenta. Por otra parte, su placer es ejercer poder, no acostarse con un anciano desconocido. Pero todavía hay otra humillación que deberán sufrir las no elegidas. Todas escucharán cómo preparan a la mujer de esa noche para su cohabitación señorial. Una servidora de confianza del señor penetra en la casa de la elegida, la hace sentar y le coloca los pies sobre un almohadón. El señor considera que hay que estimularla sexualmente haciéndole masajes en los pies. La anciana masajea los pies de la elegida golpeteando con una especie de martillito con cascabeles. El sonido se escucha en toda la casa. Las envidiosas tienen que soportar el repiqueteo en los pies de la que mereció el honor. Las relegadas se envenenan escuchando y tramando estrategias para sacar de carrera a la elegida de hoy y poder ser ellas las de mañana. Inteligente manera, por parte del señor, de estimular los celos para ser servido con mayor sumisión. 
En esa competencia por los favores del Señor, Songlian simula un embarazo que es descubierto y denunciado por su sirvienta, Yan'er. El amo del lugar la castiga negándose a visitarla en lo sucesivo, oportunidad que es aprovechada por la segunda concubina y generando expectativas en la tercera señora. El círculo de retroalimentación de los favores y castigos se nutre sin solución de continuidad. Castigos y favores, de parte del Señor y también entre las concubinas y sirvientes. Al igual que el Estado comunista, distribuye favores a los leales y obedientes y castiga a los díscolos para disciplinarlos y encauzarlos en su redil o eliminarlos si fuera necesario. Así, la tercera concubina es castigada por su traición (tiene una relación clandestina con el médico de la familia) con la muerte. Evitan la exposición y difusión del asesinato, perpetrándose en una celda donde otras anteriormente murieron por una deslealtad similar. En una especie de campo de exterminio, minúsculo, simbólico ubicado en un lugar prohibido de ser visitado por nadie, aunque anteriormente la curiosa Songlian lo haya querido conocer. Curiosidad que es mal vista por el Señor quien le niega toda explicación. De la misma manera que el régimen comunista niega los oprobios de la represión a los ciudadanos y mucho menos a los "extranjeros". No debe conocerse al exterior de la fortificación. Songlian representa la resistencia al poder omnímodo del Señor. Quiere romper las reglas de la tradición, en las que las mujeres no tienen independencia y el confucionismo restringe el rol femenino a la esfera doméstica.

El Señor/Régimen adopta distintas estrategias de poder y las respuestas de las concubinas son variadas y representan las posibilidades de adaptación o no de la población femenina y van desde el acomodamientoadaptación de la esposa más anciana, la competencia por los favores del señor sin cuestionamientos de la segunda concubina hasta la resistencia con interpelaciones hacia el poder omnímodo del Señor/Régimen de las dos últimas que tienen como consecuencia la muerte y la alienación de las dos últimas.

El ciclo recomienza con la llegada de la quinta señora. La juvenil quinta concubina pregunta por esa mujer que ya no viste ropas orientales y da vueltas y vueltas con su antiguo traje de universitaria. "Es la cuarta concubina", le dicen. No hay más preguntas. La jovencita no sabe, por supuesto, que ella es sumamente necesaria en aquel dispositivo de poder, como lo es el casamiento del cual es protagonista. No es conveniente que la única concubina que se mantiene en competencia (la segunda) acumule poder. No es conveniente que falte una mujer joven para que irrite los celos de las demás (señoras y sirvientas). Independientemente del placer que su juventud le dará al señor.

En lugar de explorar nuevas libertades, las mujeres cuyas vidas están completamente circunscriptas por las opresivas reglas tradicionales, pelean por pequeños espacios de autonomía dentro del Sanheyuan.

En un dispositivo de poder cada pieza es intercambiable. Por eso los protagonistas pierden sus nombres propios, como el enfermo en un hospital, como el preso en una cárcel, como el interno en cualquier encierro. Cada uno pasa a ser un simple número. Lo importante, en el ejercicio del poder no son las personas, sino las estrategias. Por eso en el clímax del relato que nos ocupa el amo no aparece. Él no necesita aparecer, lo que flota en el ambiente es su poder simbólico, de la misma manera que el Estado y sus dispositivos coercitivos operan y disciplinan al realizarse en actos concretos, como la represión en la Plaza de Tiannamen de 1989.

Palabras finales

La estructura narrativa de la película dividida en las estaciones del año, así como el final de la misma con la aparición de la nueva concubina, nos preanuncia un final conocido. No observamos en el director una posición 
optimista en cuanto a la posibilidad de un cambio político o en el rol asignado a la mujer. Aparecen los elementos de continuidad de la cultura tradicional, de modo que el régimen comunista moderno se presentaría como un neotradicionalismo acentuado en sus aspectos patriarcales. Allí es donde se posa la mirada del director y la crítica del mismo no sólo a la sociedad tradicional sino en aquello que el propio régimen acentúa y sostiene.

Sin embargo, una luz efímera se ve cuando aparece el hijo mayor del Señor, agente de continuidad de las tradiciones pero vulnerable a las demandas de Songlian quien actúa de una manera más decidida, sin los autocontroles que se impone ante el Señor. Aparece un rasgo más simétrico de relación entre géneros que podría interpretarse como un cambio generacional. Pero no vemos en la película una apuesta a que en las futuras generaciones la matriz del régimen político sufra transformaciones significativas. Tal vez ese optimismo no sea parte de su visión a largo plazo. Y después de todo, no tendría por qué serlo.

\section{Notas}

1. En 1966 por impulso de Mao Zedong, se pone en marcha el proceso político conocido como Revolución Cultural, que no fue otra cosa que el intento de depuración de los disidentes y opositores del partido y del estado. El mismo tuvo lugar entre 1966 y 1969 y cuyo brazo ejecutor fueron los Guardias Rojos, 20 millones de jóvenes maoístas respaldados por el ejército de Lin Biao, que actuaron con completa impunidad y por cuya acción se produjeron más de 3 millones de ejecuciones. Además del pánico generalizad, se produjo el destierro a granjas agrícolas o a fábricas populares, de miles de estudiantes, intelectuales, escritores, disidentes políticos, entre los que se encontraba el propio Zhang Yimou, (situación por la que atravesó entre los 18 y los 21 años de edad), con el fin de reeducarlos. Para una profundización del tema ver Bianco, 1987; Bailey, 2002; Meisner, 2007.

2. Ficha técnica. Nacionalidad: China. Producción: Era Internacional (Hong Kong) Ltd. Productor: Chiu-Fusheng. Guión : Ni-Zhen, según la novela Un grupo de mujeres y concubinas, de Su-Tong. Fotografía: Zhao-Fei y Yang Lun. Dirección artística: Cao-Kuping y Dong Huamiao. Montaje: Du-Yuan. Música: Zhao-Jiping

Ficha artística: Gong Li (Songlian), Ma-Jingwu (Chen-Zhaochian), He-Caifei (la Tercera Concubina), GaoCiufeng (la Segunda Concubina), Jin-Shuyan (la Primera Señora) y Kong-Lin (Yan’er).

Galardones: 1991, Premio Oscar de Oro a una de las Diez Mejores Películas Chinas en el Festival de Cine de Hong Kong. 1991: Premio León de Plata en el Festival de Cine de Venecia (Italia). 1992; Nominación al Oscar a la Mejor Película Extranjera (EEUU). El gobierno esta vez, si autorizó su asistencia a la ceremonia, habida cuenta que recibió una nominación similar para su anterior film Judou(1989) y se prohibió su participación en la misma.

3. Las protestas de trabajadores y estudiantes reclamando una mayor apertura democrá- tica se produjeron entre abril y junio de 1989. Las mismas fueron reprimidas ferozmente por el gobierno chino, fundamentalmente en los días 3 y 4 de junio y tuvo un saldo de víctimas fatales y de heridos que se cuentan por centenares. Como consecuencia de la masacre se creó El movimiento de las Madres de Tiannamen. Sobre el particular véase Liu Xiaobo, 2012. 
4. Etapa que abarca desde 1913 hasta fines de la década de los 20 cuando el ejército nacionalista comandado por Chiang Kai Shek derrota al último señor de la guerra del norte. El objetivo era la unificación de China, fragmentada políticamente entre diversos caudillos militares opuestos a la constitución de una república unificada. Véase Spence, 2011.

\section{Bibliografía}

Alcaine, R. y Chen, M. (1998). Zhang Yimou. Madrid: Ediciones JC. Colección Directores de Cine N 51.

Bailey, P. (2002). China en el siglo XX. Barcelona: Ariel Pueblos.

Bianco, L. (1987). Asia Contemporánea. México: Siglo XXI.

Liu, X. (2012). No tengo enemigos, no conozco el odio. Buenos Aires: Emecé.

Foucault, M. (1989). Vigilar y Castigar. Nacimiento de la prisión. Buenos Aires : Siglo XXI.

Foucault, M. (2002). Historia de la Sexualidad. Tomo 1 La voluntad del saber. Buenos Aires: Siglo XXI.

Meisner, M. (2007). La China de Mao y después. Una historia de la República Popular. Buenos Aires: Comunicarte.

Spence, J. (2011). En busca de la China moderna. México: 85 Tiempo de Memoria TUSQUETS editores.

Abstract: The film can be interpreted as an aesthetic representation of the meticulous mechanisms of the exercise of power that have as purpose -as it's proposed by Michel Foucault in the different stretches of his work-, to discipline and normalize those who pretend to question it. Foucault put it in reference to the modern forms of the army, the school, the prisons, hospitals, which we can extend to gender relations, a topic not dealt with by the author.

In the Red Lantern, the filmic representations of authoritarianism are not only associated with the everyday life of women subordinated to the law of the male, both socially and culturally, but can be interpreted as the construction of a kind of disciplining power that crosses the different political regimes of the history of China of the twentieth century. Filmed shortly after the repression in Tiananmen Square, the powerful images of power and patriarchy represent the traditional moral norms of Confucianism and re-signify, by extension, those of Communist China.

Key words: power - authoritarianism - patriarchy - Confucianism - Communist China

Resumo: O filme pode ser visto como uma representação estética dos mecanismos detalhados de governança que se destinam e, como afirma Michel Foucault em diferentes seções da sua obra, disciplinar e normalizar os que procuram questioná-lo. Foucault o analisa referindo-se às formas modernas do Exército, escolas, prisões, hospitais, que podem ser estendidos às relações de gênero, tema não abordado pelo autor. 
No fime O farol vermelho, as representações cinematográficas do autoritarismo não estão somente associadas com a vida diária de mulheres subordinadas à lei do homem, tanto socialmente como culturalmente, mas pode ser interpretado como a construção de uma espécie de poder disciplinador que atravessa os diferentes regimes políticos da história da China do século XX. Filmado logo após da repressão na Praça Tiananmen, as imagens sobre o poder e o patriarcado representam padrões morais tradicionais do confucionismo e resinificam por extensão, ás da China comunista.

Palavras chave: poder - autoritarismo - patriarcado - confucionismo - China comunista.

Poder estatal y dominación de género: sus representaciones en La linterna roja (China, 1991) de Zhang Yimou fue publicado de la página 19 a página26 en Cuadernos del Centro de Estudios de Diseño y Comunicación Nº 